\title{
ASPECTOS TEÓRICOS DOS CUIDADOS PRIMÁRIOS DE SAÚDE *
}

Nilce Piva Adami * *

ADAMI, N.P. Aspectos teóricos dos cuidados primários de saúde. Rev. Esc. Enf. USP, São Paulo, $14(3): 229-235,1980$.

A autora apresenta em linhas gerais a fundamentaçöo tebrica dos cuidados primários de saúde. Destaca alguns encontros internacionais e nacionais que recomendam a extensáo das afoes de saude d̀ população. Delinea também, a nova proposta de reordenaçäo e expanséto do sistema de serviços de saude. Por ultimo, cita algumas estratégias operativas visando a extensío da cobertura ¿ populaçāo.

\section{INTRODUÇÃO}

O momento atual evidencia, no cenário mundial, uma situação nada aceitável em termos de oferta de serviços de saúde à população, principalmente nos países em desenvolvimento.

A literatura específica e compromissos assumidos pelos vários governos da comunidade internacional demonstram uma tomada de posiçăo em face do desafio que constitui a responsabilidade de universalizar o direito dos cuidados à saúde, uma das múltiplas dimensōes do desenvolvimento sócio-econômico.

Neste enfoque, a assistência primária configura-se numa das estratégias adotadas pelo Sistema de Serviços de Saúde visando a ampliar a cobertura assistencial oferecida à comunidade. Desta forma, a organização e operacionalização de uma rede básica de serviços de saúde propiciaria a viabilização do alcance da meta proposta - "Saúde para todos no ano 2.000 " - atendendo ao postulado ético aceito por todos, o de ser a saúde considerada como um direito fundamental do ser humano.

$\mathrm{Na}$ abordagem do embasamento teórico dos cuidados primários de saúde, optouse pela divisão deste trabalho em três partes, explicitadas como segue.

1a.) Principais marcos de referência internacionais e nacionais que recomendam a extensão das açōes de saúde à populaçăo objetivando cobertura universal.

2a.) Delineamento de uma nova proposta para o Sistema de Serviços de Saúde, tendo em vista a ordenação e expansão de atividades básicas de saúde, a um custo compatível com a economia brasileira.

3a.) Algumas estratégias operacionais que contribuem para que o Sistema de Serviços de Saúde alcance sua finalidade, ou seja, a melhoria do nível de saúde como parte do bem-estar da comunidade.

- Trabalho apresentado no Simpósio “Assistência Primária de Saúde”, promovido pela ABEn-S.P., realizado no dia 7 de abril de 1980.

* Professor Assistente Doutor do Departamento de Prática de Saúde Pública da Faculdade de Saúde Pública da USP. 


\section{MARCOS DE REFERENCIAS INTERNACIONAIS E NACIONAIS}

\subsection{Plano Decenal de Saúde para as Américas 6,7}

A III Reunião Especial de Ministros de Saúde das Américas, realizada no Chile em 1972, centrou seus esforços ao redor de um objetivo primordial que foi o de propor a extensð̃o de cobertura das açðes de saúde às populaçð̃es de áreas rurais, mediante a regionalização dos serviços. Tendo por base os níveis e funçбes do sistema regionalizado preconizado pelo Plano, concluiu-se que há necessidade de se efetivarem mudanças no processo de formação e utilização dos recursos humanos. Tais mudanças referem-se a um aumento significativo de pessoal auxiliar destinado ao nível periférico do sistema e inovaçðes na formação dos profissionais do grupo da saúde.

\subsection{Reunião Especial de Ministros de Saúde das Américas 5}

Essa Reunião desenvolveu-se na Capital dos Estados Unidos da América, em setembro de 1977. Nesse encontro, os Ministros confirmaram o propósito anterior de intensificar os esforços no sentido de ativar o processo de extensão de cobertura dos serviços de saúde a toda a população, priorizando, no entanto, os núcleos marginalizados e sub-atendidos dos meios rural e urbano. Como componente essencial para atingir essa finalidade, adotaram-se as estratégias de cuidados primários e de participação da comunidade; como instrumentos, a racionalização do processo administrativo e o desenvolvimento de tecnologias apropriadas ao fim proposto com seus atributos de universalidade, integralidade, acessibilidade, efetividade e continuidade no contexto do desenvolvimento sócio-econômico dos países signatários.

\subsection{Conferência Internacional sobre Assistência Primária de Saúde 3}

O informe da IV Reunião Especial de Ministros constituiu a contribuição da Regiá das Américas para a Conferéncia Internacional sobre Assistência Primária de Saúde, realizada um ano mais tarde, em setembro de 1978, em Alma-Ata, URSS, e patrocinada pela Organização Mundial de Saúde (OMS) e Fundo das Naçбes Unidas para a Infância (UNICEF).

No documento desse encontro internacional ficou evidenciado que o cuidado primário constitui o meio para "se alcançar, em todo o mundo e num futuro previsível, um nível aceitável de saúde, que forme parte do desenvolvimento social e se inspire num espírito de justiça". Essa modalidade de assistência foi considerada válida para todos os países do mundo, configurando-se, no entanto, como necessidade premente, sobretudo para os países em desenvolvimento.

\subsection{V, VI e VII Conferências Nacionais de Saúde 1,4,9,10}

Em nosso País, as três últimas Conferências Nacionais de Saúde, realizadas em Brasilia em 1975, 1977 e 1980, incluíram em seus temas básicos, respectivamente:

- a extensão das açб̃es de saúde às populaçoes rurais;

- a interiorização dos serviços de saúde por meio do Programa de Interiorização das Açðes de Saúde e Saneamento (PIASS), na regiåo Nordeste; e

- a extensáo das açð̃es de saúde através de serviços básicos, constituindo, portanto, um Programa Nacional prioritário e axial da Política de Saúde do Governo, uma vez que visa toda a população brasileira. Oportuniza, porém, a primazia para o atendimento das populaçðes rurais, de pequenos centros e das periferias de grandes cidades. 


\section{NOVA PROPOSTA PARA O SISTEMA DE SERVIÇOS DE SAÚdE $1,2,4,8$}

Devido à experiência acumulada em diversos países do mundo, passou-se a recomendar, atualmente, que todos os serviços de saúde existentes desenvolvam, de forma integrada, açðes de promoçāo, proteção e recuperação da saúde. Esses serviços devem estar hierarquizados numa rede regionalizada, de complexidade crescente, incluindo desde as unidades mais simples, localizadas o mais próximo possivel do domicílio do cliente, até o complexo hospital universitário visando prestar assistência médicohospitalar.

Além do aspecto da integralidade das açōes, é indispensável que as unidades sejam de fácil acesso - geográfico, econêmico e cultural - aos usuários, a fim de estimular a demanda aos serviços de cuidados primários. Deve existir, também, um sistema de referência e contra-referência de pacientes, ao longo dessa pirâmide assistencial.

Neste reordenamento dos serviços de saúde adquire relevo o processo de regionalização, com organização escalonada de níveis e unidades de atendimento e adscrição de coberturas específicas - geográficas e populacionais - a cada unidade assistencial ou de apoio.

\subsection{Niveis de Assistência}

Numa rede de serviços de saúde hierarquizados em niveis de complexidade crescente, habitualmente esses níveis săo classificados em cuidados primários, secundários e terciários a seguir definidos.

\subsubsection{Cuidados Primários}

Consistem nos cuidados prestados no nível periférico do sistema. Esses cuidados são realizados por médico generalista, outros profissionais como enfermeira(o), dentista, etc. e pessoal técnico, auxiliar e elementar.

Este nível de assistência serve como ponto de entrada, primeiro contato, triagem e referência para os demais níveis do sistema de saúde.

Deve prover uma gama de serviços básicos in đispensáveis à preservação e à recuperação da saúde, dirigidos a três esferas de ação, a saber:

a. às pessoas, incluindo:

- as imunizaçðes obrigatórias;

- o controle de grupos biológica e socialmente mais vulneráveis e de maior risco, como por exemplo: atendimento sistematizado de gestantes e crianças, hipertensos e diabéticos;

- o reconhecimento e tratamento de afeç̧⿸丆es e traumatismos mais comuns, tais como: gripe, tosse, diarréia, febre, verminoses, algumas dermatites, ferimentos e outras demandas de primeiros socorros;

- promoção da melhoria da alimentação para os grupos de maior risco;

- consulta médica geral e encaminhamento de clientes aos níveis mais complexos do sistema, quando necessário, e acompanhamento dos retornos;

b. ao meio ambiente, compreendendo:

- o desenvolvimento de açoes destinadas à melhoria do saneamento básico, visando soluçбes de abastecimento de água e destino dos dejetos ao nível domiciliar; 
c. de apoio, abrangendo:

- realização de alguns exames laboratoriais, quando possível, e colheita e envio de material ao laboratório de referência;

- elaboração de relatórios de produção diários e mensais e realização de outras atividades burocráticas; $e$

- delimitação de cobertura da população de referência do Posto, a fim de possibilitar a operacionalização das atividades sem queda da qualidade e permitir avaliaçбes periódicas, utilizando-se indicadores apropriados.

As unidades executoras desses cuidados primários abrangem dois sub-níveis:

- um deles, o mais simples - tipo Posto de Saúde - operado por pessoal auxiliar, recrutado preferentemente na própria localidade do serviço de saúde; estes Postos, na dependência das suas características e da facilidade de acesso a outras unidades, poderão ou não receber periodicamente a visita de um médico para dar consultas agendad as previamente pelos auxiliares.

- o segundo sub-nível é o Centro de Saúde que deverá executar todas as atividades do Posto, acrescidas de assistência médica permanente, vigilância epidemiológica e exames laboratoriais simples. Estas unidades devem proporcionar apoio técnico e administrativo a um determinado número de Postos e devem atender à clientela encaminhad a por essas unidades elementares.

Em suma, o nível executor dos cuidados primários é o fundamento de um amplo patamar de um sistema hierarquizado e regionalizado. É o nível capaz de solucionar cerca de dois terços das necessidades de saúde de nossa população, dada a freqüência de doenças simples, auto-curáveis, que exigem cuidados mínimos ou a aplicação de procedimentos pré-estabelecidos, conforme demonstram dados empíricos e de pesquisas internacionais, confirmadas por estudos já realizados no Brasil.

A simplicidade dos cuidados primários não deve, porém, ser confundida com baixa qualidade das açôes de saúde, mas deve ser entendida como uma simplificação de meios correspondentes à simplicidade dos problemas. 0 acesso a serviços mais complexos deverá ser assegurado a toda clientela que apresentar problemas de saúde que exigem uma assistência intermediária ou mais especializada, proporcionada pelos outros níveis assistenciais.

\subsubsection{Cuidados Secundairios}

São os cuidados prestados nos hospitais de comunidade, unidades mistas e também em ambulatórios com especialistas visando ao esclarecimento de diagnóstico e ao tratamento, incompatíveis com a tecnologia simplificada existente nas unidades de cuidados primários. Em linhas gerais, prestam serviços médico-cirúrgicos, gineco-obstétricos e pediátricos e utilizam tecnologias intermediárias; devem servir a populaç̃es abrangidas por várias unidades de assistência primária.

\subsubsection{Cuidados Terciários}

Incluem os cuidados prestados em hospitais gerais, com as especialidades mais comuns da medicina e da cirurgia, constituindo o recurso máximo de saúde da regiáo, à qual servem como hospitais de base ou de referência. Neste nível são alocados recursos humanos e materiais compostos de super especialistas, utilizando tecnologia complexa e voltados ao diagnóstico e tratamento de doenças mais raras ou complexas. Em geral, tais serviços servem como campos de prática para Faculdades de Medicina e de outras áreas da saúde. 


\subsubsection{Cuidados Quaternários}

Convém citar ainda, como cuidados quaternários, os serviços prestados em ambulatórios e hospitais altamente especializados, campos destinados ao desenvolvimento da pesquisa e de tecnologias assistenciais e que são considerados núcleos de referência para várias regiőes de saúde.

A utilização adequada dos diferentes níveis assistenciais será viabilizada na medida em que existirem programaçðes que definam, claramente, para os profissionais que atuam na rede, quais os recursos a serem mobilizados para cada condição de atendimento.

Em termos disciplinadores da utilização dos recursos e para tornar menos custosa a assistência, a rede básica deve constituir, sempre, a porta de entrada dos clientes no sistema de saúde, excetuando, naturalmente, as emergências mais complexas.

Uma rede básica de serviços de assistência primária tendo como módulos um conjunto de unidades periféricas, supervisionado por um Centro de Saúde, tem se mostrado em várias experiências, tanto dentro como fora do País, solução segura e economicamente viável para se alcançar a desejada extensão de cobertura.

\section{ESTRATEGIAS OPERATIVAS $1,2,4$}

\subsection{Máxima Extensão de Cobertura dos Serviços de Saúde}

Compreende-se que a máxima extensão de cobertura das açð̃es de saúde será alcançada quando for possível, à cada Estado, dispor de serviços básicos que atendam às necessidades de toda a população, localizados de forma acessível e que sejam aceitos por essa população.

\subsection{Participação Comunitária}

É imprescindivel a participação da comunidade em todas as etapas do processo assistencial, por meio de alguns mecanismos de expressáo, tais como: formas organizativas e lideranças formais; esta participação propicia condições para melhor aceitação dos serviços a serem implantados ou em execução, o que acontecerá na medida em que as unidades de saúde atendam às reais necessidades da população.

\subsection{Recursos Humanos}

A formação e a utilização de recursos humanos constitui o ponto nodal do desenvolvimento dos serviços básicos de saúde.

E emergente nesta área uma nova posição funcional a ser adotada pela equipe de saúde, na qual sobressai ampla utilização de pessoal de níveis auxiliar e elementar. Este pessoal deverá ser recrutado na própria comunidade onde atuará, em condições de resolver os problemas que não requerem a direta participação de profissionais de nível superior. Para tanto, é indispensável preparação adequada e esquemas apropriados de apoio e supervisão.

\subsection{Regionalizaçđo}

Para o alcance dos objetivos fundamentais propostos - extensão de cobertura, ampla participação comunitária e integralização das ações de saúde - a regionalização é imprescindível como instrumento de implantação e operação da rede de serviços de saúde; esta regionalização deve ter por base critérios geográficos e demográficos 
e aplicar os princípios adequados para organizar esses serviços, princípios estes que podem ser sumariados em três tipos: epidemiológicos, tecnológicos e organizacionais.

\section{COMENTARIOS FINAIS}

Finalizando, gostariamos de salientar outros pontos fundamentais que devem ser considerados, tendo em vista nova proposta de trabalho para o Sistema de Serviços Saúde.

4.1 Em nosso País, existem, possivelmente, mais de $\mathbf{4 0}$ milhōes de pessoas que não têm acesso aos serviços de saúde.

\subsection{Os serviços atualmente prestados são inadequados às nossas necessidades.}

4.3 O conhecimento e a tecnologia disponíveis no País, em relação aos problemas de saúde prevalentes, são significativos, em muitos casos suficientes e nossa capacidade de acionálos está sub-utilizada.

Diante deste quadro é propósito do Governo acelerar um processo renovador no setor saude para beneficiar todos os brasileiros. Esse processo se configura num repto para os profissionais da saude e, em grande parte, para enfermeiras(os) em face das necessidades prementes de:

- preparo de grande número de pessoal auxiliar e da comunidade para os cuidados primários, ajustado aos requisitos da prática, assegurando também a característica contínua da educação por meio de supervisão e reciclagens oportunas;

- educação em serviço a fim de atualizar de forma sistematizada os enfermeiros para a prática dos cuidados primários desenvolvidos em Centros de Saúde;e

- reflexăo crítica calcada no currículo de enfermagem para questionar se estamos formando os profissionais requeridos para todos os níveis assistenciais do Sistema de Serviços de Saude.

ADAMI, N.P. Theoretical aspects of the primary health care. Rev. Esc. Enf. USP, São Paulo, $14(3): 229.235,1980$.

The outhor presents a article of the foundations of primary health care. She refers to some international and national meetings that recommend the extension of health care to the whole population; she also designs the new proposal for reorganization and extension of the Health Service System and describes some operative strategies to accomplish such extension.

\section{REFERENCIAS BIBLIOGRAFICAS}

1. BRASIL. Ministério da Saúde. Proposição de diretrizes. Uma contribuição (versão preliminar). (Trabalho apresentado na Vil Conferência Nacional de Saúde, Brasília, 1980).

2. CHAVES, M.M. Regionalizacão docente-assistencial e níveis de assistência. Rev. Adm. públ, Rio de Janeiro, 11 (3): 69-80, 1977.

3. CONFERENCIA INTERNACIONAL SOBRE ATENCION PRIMARIA DE SALUD

1a., Alma-Ata (URSS), 6-12 set. 1978. Atención primária de salud: informe conjunto . . Ginebra, Organizacion Mundial de la Salud, 1978.

4. MACEDO, C.G. Extensão das açōes de saúde através dos serviços básicos. (Trabalho apresentado na ViI Conferência Nacional de Saúde, Brasília, 1980). 
5. ORGANIZAÇÃo PANAMERICANA DE SAÜDE. Extensão da cobertura dos serviços de saúde baseada nas estratégias de assistência primária e participaçōo da comunidade. Washington, 1977. (REMSA 4/40).

6. ORGANIZACION PANAMERICANA DE LA SALUD. Plan decenal de la salud para las Américas. Washington, 1972. (REMSA 3/30).

7. PILLET, J.V. La extensión de la cobertura de los servícios de salud y los recursos humanos. Educ. med. Salud, Washington 7 (3/4): $351-75,1973$.

8. SANTOS, N.R. Atenç̄o primária em saúde - um posicionamento. Campinas, 1979 (mimeografado).

9. SEIXAS, J.C. Interiorização dos Serviços de Saúde. In: CONFERÊNCIA NACIONAL DE SAÚDE, 6a., Brasília, 1977. Anais. Brasília, Ministério da Saúde, 1977. p. 139-50.

10. VILLAS BOAS, A. Extensão das açōes de saúde às populaçōes. In: CONFERENCIA NACIONAL DE SAUDE, 5a., Brasília, 1975. Anais. Brasília, Ministério da Saúde, 1975. p. $219-42$. 